\title{
蛋 OSETLJIVOST ULOGE VOJSKE U BORBI PROTIV SAVREMENOG TERORIZMA
}

Dragan Jevtić, Željko Pajović i Aleksandar Dumić Univerzitet odbrane u Beogradu, Vojna Akademija

Očigledno je da će borba protiv globalnog terorizma potrajati dugo i biti naporna. Kao deo sistema bezbednosti jedne zemlje, vojska ima značajnu ulogu u borbi protiv ove pojave. U okolnostima određenih političkih i socijalnih uslova u društvu, upotreba vojske bi mogla da prouzrokuje negativne posledice na buduće unutrašnje političke odnose i ostvarivanje prava i sloboda građana u tom društvu. U izvršenju svoje uloge, vojska bi u ovoj borbi mogla da utiče na eskalaciju sukoba, kao i da podstiče stvaranje novih terorista. Ovaj rad ima za cilj da kritički razmotri efekte i posledice koje su vezane za osetljivost uloge vojske, a samim tim i njenu upotrebu u savremenoj borbi protiv terorizma.

Ključne reči: uloga vojske, terorizam, borba, pobuna, sloboda

Uvod

I poslednje dve decenije Evropska unija (EU) je nametnula stav da uloga vojske u demokratskim društvima ne bi trebala da bude fokusirana na unutrašnje pretnje. Ovo se manifestuje preko više trendova, predavanjem bezbednosti granica evropskih zemalja u ruke snaga unutrašnje bezbednosti - policiji, kao i smanjivanjem aktivnih sastava i odbacivanjem sistema regrutacije u velikom broju zemalja. EU je uvela trend demilitarizacije država fokusirajući se ka unutrašnjoj bezbednosti i izgradnji vojne sposobnosti usmerene spolja, kao delu sistema kolektivne bezbednosti.

Međutim, sa terorističkim napadima u Parizu „EU se probudila u novoj paradigmi: vojske na ulicama Francuske, Belgije i drugih zemalja, kao i izjave nekih vlada o povećanju vojnih budžeta i vojne intervencije protiv terorista u Siriji“. ${ }^{\prime}$

Sa druge strane, postavlja se pitanje da li je vojska neophodna u savremenoj borbi protiv terorizma, tj. da li ona ima značajnu ulogu u ovoj borbi? Praksa pokazuje da su zemlje koje su koristile pristup održavanja sukoba niskog intenziteta imale bolji uspeh u borbi protiv terorizma nego što su to imale zemlje koje su sa korišćenjem vojske eskalirale situaciju u sukob visokog intenziteta. Uvažavajući činjenicu da SAD i NATO nisu uspele da pobede terorizam sa upotrebom vojske u Avganistanu u prošlih 15 godina, postavlja se pitanje da li je takva strategija neprikladna?

\footnotetext{
${ }^{1}$ Geir Moulson, German Cabinet Approves Military Intervention Against ISIS In Syria, The World Post, 2015, dostupno na: http://www.huffingtonpost.com/entry/germany-isis-syria_565dae34e4b072e9d1c32977, 30.10.2016. godine.
} 


\section{Definisanje pojma savremenog terorizma i njegovi oblici}

U međunarodnom pravu još nije postignut konsenzus o opšte prihvaćenoj definiciji terorizma. Što se tiče njegove taktike i tehnike ratovanja, i pored brojnih definicija, teorija se još uvek suočava sa izazovom da napravi jasnu razliku između pobune, terorizma, ustanka, nereda i ratova nacionalnog oslobođenja.

Često ponavljani kliše u međunarodnoj politici je „da onaj ko je terorista za neke, za druge je borac za ljudska prava“. ${ }^{2}$ Takva percepcija je glavni predmet rasprave u međunarodnoj zajednici (MZ), jer ona pre svega zavisi od operativnog pristupa pojedinih država prema savremenoj borbi protiv terorizma.

Akademske definicije terorizma potvrđuju da su najčešći elementi definicije terorizma nasilje kao metod, građani i vlada kao mete, izazivanje straha i iznuđivanje političkih ili socijalnih promena kao ciljevi, a veliki broj žrtava (kome teže teroristi) ukazuje na spektakularnost kao definicioni elemenat terorizma. Politički motiv izvršioca je uslov da se neka radnja označi kao teroristička, jer je to jedina definicijska komponenta koja razdvaja terorizam od običnog kriminala. Budući da se značenje termina terorizam menjalo kroz istoriju kako bi se prilagodilo političkom riziku svakog narednog perioda - veoma je teško odrediti jednu trajnu definiciju terorizma. Najveći broj autora smatra da je politička komponenta jedna od bitnijih elemenata terorizma. To se može zapaziti i u bilateralnim ugovorima, zatim u zakonodavstvima velikog broja zemalja, kao i u dokumentima represivnih državnih organa.

Analizirajući dosadašnje definicije terorizma, jasno se uočavaju sledeći elementi terorizma: nasilje, strah, cilj i motiv. Nasiljem se demonstrira sila koja ima za cilj da prouzrokuje određene psihološke efekte (osećaja nesigurnosti, straha). U literaturi postoji visok stepen saglasnosti o tome da je nasilje najrelevantnija komponenta pri definisanju terorizma. Motiv terorista da izvrše nasilje za naučnike je još uvek nedostupan element terorističke aktivnosti. Terorističke aktivnosti nikada nemaju masovnu podršku građana i stanovništva. U slučaju da je imaju - onda to više nije terorizam, već se radi o gerili ili masovnom ustanku stanovništva. Zahtevi terorista nikada nisu realni niti utemeljeni na zakonu.

Uzroke savremenog terorizma možemo tražiti u zaoštravanju borbi razvijenih zemalja i velikih korporacija za prestiž na tržištu rada i kapitala. Njihov sukob temelji se na želji za sve većim bogaćenjem i kontrolom vitalnih izvora energije, strateških materijala i tržišta, ekonomskom jazu između razvijenih i nerazvijenih zemalja sveta, slabljenju značaja međunarodnog pravnog poretka i demokratizaciji međunarodnih odnosa.

Postoji niz primera iz nedavne prošlosti kada su se, pod okriljem uspostave demokratije i demokratskih poredaka, pojedine svetske sile uključile kao „svetski policajac“, te preuzele kontrolu u manjim i nerazvijenim zemljama sveta bogatih prirodnim izvorima nafte, plina i drugih energenata, pod izgovorom uspostave demokratskih načela vladanja i zaštite demokratskih prava svojih građana na teritoriji drugih zemalja (Irak, Avganistan, Libija, Sirija...).

Činjenica je da međunarodni pravni poredak nije identičan u svim državama sveta pa tako ni u našem neposrednom okruženju. Države članice Evropske unije nastojale su postići konsenzus i svoje domaće kazneno-pravno zakonodavstvo usaglasiti sa zakonodavstvom Evropske unije u pogledu definisanja borbe protiv terorizma, organizovanja i finan-

\footnotetext{
${ }^{2}$ David Benest, British Leaders and Irregular Warfare in The Moral Dimension of Asymmetrical Warfare, The Netherlands, 2009, p.170.
} 
siranja kriminala kroz razne ilegalne izvore, u čemu su delimično uspele. Svaka država nastojala je kroz svoje domaće zakonodavstvo zadržati pravo na suverenitet te pravo na vlastitu borbu i zaštitu građana na svojoj teritoriji. Stoga danas imamo bitne razlike u pogledu i odnosu na terorizam i teroristički čin između različitih država i njihovih zakonodavstava. Zemlje koje još uvek nisu direktno ugrožene terorizmom imaju puno blaže kriterijume i stavove u kazneno-pravnom definisanju terorizma.

Tako svako posedovanje oružja, opasnog oruđa, eksploziva, eksplozivnih naprava i uređaja za čije poreklo građanin nema ili ne posjeduje dozvolu ili odobrenje, u pojedinim se državama smatra direktnim terorističkim činom, a građanina proglašava teroristom sa predviđenim rigoroznim merama i kaznama.

Govoreći o terorizmu kao tipu nasilja, isti se može podeliti na oružani i neoružani, a danas se sve više govori i o otvorenom i prikrivenom terorizmu u svetu. Otvoreni terorizam najčešće izvode terorističke i ekstremističke organizacije samostalno ili pod pokroviteljstvom neke zainteresovane vlade s ciljem zastupanja svojih političkih i kriminalnih ciljeva, koji se podudaraju s ciljevima države, odnosno vlade pod čijim su pokroviteljstvom.

Za razliku od otvorenog terorizma, prikriveni terorizam se najčešće izvodi i planira od strane država u sklopu tzv. specijalnog rata protiv neke države, vlastitim snagama ili uz pomoć ekstremističkih i kriminalnih organizacija, a provodi se u tajnosti s ciljem slabljenja države nakon čega slede drugi otvoreni oblici konvencionalnog i nekonvencionalnog ratovanja. Tu se uglavnom koriste slabosti napadnute države u društvenom, ekonomskom, finansijskom, ekološkom i drugom smislu. Najčešće je to namerno izazivanje raznih zaraznih i epidemijskih bolesti kod ljudi, životinja i biljaka ili namerno izazivanje nacionalne netrpeljivosti, sukoba i nasilja, kao i puštanje u opticaj krivotvorenih novčanica, kriminal u privatizaciji i dr.

Ekološki (nuklearni, hemijski i biološki) i sajber terorizam moramo shvatati ozbiljno, jer iako još uvek netipične vrste ugrožavanja, one mogu prouzrokovati velike i teške posledice (napad u podzemnoj železnici u Tokiju 1995. godine kada je korišćen sarin). Sredstva, materijali, kao i potrebno znanje za izradu biološkog i hemijskog oružja danas su lako dostupni i nisu skupi, pa i siromašnije terorističke organizacije mogu posegnuti za takvim rešenjima.

Sajber terorizam koristi nove, modernije i tehnološki sofisticiranije sisteme i metodologiju kojom se napada na neki politički sistem. Opasnost je dvojaka: teroristi uz pomoć interneta mogu naneti nesagledive posledice po društvo (otežano telefonsko komuniciranje, problemi u prometu, sabotiranje funkcionisanja berze itd.), a ujedno ga koriste kao način komunikacije, kako međusobno, tako i prema javnosti, te kao oružje.

\section{Promene, trendovi i izazovi upotrebe vojske u borbi protiv savremenog terorizma}

Izazov u borbi protiv terorizma u poslednjih nekoliko decenija predstavljaju pokreti koji su u mnogim slučajevima blisko povezani sa etnonacionalističkim i verskim razlozima, političkim borbama za prevlast, ekstremnim grupama koje traže podelu vlasti itd., gde terorizam je samo sredstvo a ne cilj sam po sebi. Prema tome, postoji dugogodišnja debata oko toga da li je terorizam krivično delo ili čin rata, i koji je pravi razlog da se grupa koja koristi teror opredeli za ekstremno nasilje protiv države. Strategija koja bi se upotrebila u borbi protiv terorizma zavisi od načina percipiranja ove pretnje. 
Obično, prioritetne snage u borbi protiv terorizma su policijske. Razlog za to je rešavanje problema pre njegovog eskaliranja, odnosno održavanje sukoba na nivou niskog intenziteta. Kada je reč o identifikovanoj pobuni, vlade obično preduzimaju mnogo veće mere. U tom slučaju neophodna je koordinacija svih državnih resursa i integracija svih političkih, socioekonomskih, pravnih, policijskih i vojnih sposobnosti kako bi se pobuna neutralizovala.

Mutacija savremenog terorizma je praćena rastućim trendom većeg angažovanja vojne snage u borbi protiv terorizma. Ovaj trend nije uzrokovan samo radi toga što kapaciteti policije nisu dovoljni, već što priroda terorizma postaje još ratobornija. Ako se pre tri decenije pretnja sastojala od tzv. usamljenih vukova i malih terorističkih grupa sa ograničenim ciljevima, sa pojavom Al-Kaide terorizam je postao globalna pretnja. Terorističke organizacije kao Al-Kaide i aktuelne Islamske države ${ }^{3}$ imaju dugoročnu viziju, globalne ambicije i zapadnim demokratijama su praktično proglasile totalni rat.

Postoji dilema o tome kakva je uloga vojske u savremenoj borbi protiv terorizma, kolika je efikasnost a kolika je šteta od upotrebe vojske u savremenoj borbi protiv terorizma, obzirom da angažovanje velikih snaga gura sukob od niskog ka visokom intenzitetu.

U uslovima koji postoje u današnje vreme, sa pojavom transnacionalnog terorizma koji ne poznaje granice, ono što se dešava u jednoj zemlji, ima veliki uticaj na međunarodne odnose. Upotreba vojske u borbi protiv terorizma može imati implikacije, prvenstveno na samu državu, a zatim i na međunarodne odnose. Zbog toga je neophodno da se zaista vidi da li je vojno angažovanje efikasnije od angažovanja policijskih snaga, odnosno, da li organizaciona kultura vojske daje adekvatan odgovor na savremeni terorizam. U ovom trenutku čini se da samo ponašanje terorista nameće vojni odgovor. Veliki broj svetskih teoretičara i analitičara se slažu da je to upravo i cilj terorista.

Opšte prihvaćeno mišljenje je „da je namera terorista bila da primoraju zapadne demokratije da žrtvuju slobodu na uštrb bezbednosti“. ${ }^{4}$ Prema tome, sama pojava vojnika na ulicama Evrope u 2015 godine bi se mogla protumačiti kao uspeh terorista. Teroristi u svojoj strategiji primenjuju neke gerilske opšte principe, kao navlačenje vojske da primeni nesrazmernu snagu i time da izazove kolateralnu štetu na civilno stanovništvo.

Upotreba vojske u borbi protiv terorizma može imati pozitivan uticaj na privremeno suzbijanje terorizma, ali i negativan uticaj na civilno društvo, politiku države i na ponašanje same vojske. Vojne snage u borbi protiv terorizma moraju da naprave seriju organizacionih promena, uključujući i proširenje svojih ovlašćenja u smeru obavljanja policijskih poslova. Procenjuje se da „za pobedu u okviru kampanje protiv terorizma, državne vlade moraju mobilisati deset puta više vojnika od procenjenog broja terorista", 5 što je praktično mobilizacija i rekonstrukcija države za rat. To može značiti militarizovanje civilnog društva.

Za razliku od protivpobunjeništva, ,protivterorizam u principu treba da sadrži više odbrambenih mera kako bi se umanjila sposobnost terorističke grupe da negativno utiče na stanovništvo, kao što je zabrana političkog delovanja, prisustva policije na javnim mesti-

3 Islamska država (arapski: الدولة الاسلامية في العراق والثام) je poznata i kao Islamska Država u Iraku i Levantu ili Islamska Država u Iraku i Siriji. Ona je nepriznata teroristička država formirana 03.01.2014. godine, 29.06.2014. godine je proglasila kalifat na teritoriji Iraka i Sirije.

${ }^{4}$ Andrew W. Neal, Exceptionalism and the Politics of Counter - Terrorism: Liberty, Security and the War on Terror, Routledge, London, 2010. p. 8.

${ }^{5}$ Geraint Hughes, The military's role in counterterrorism: examples and implications for liberal democracies, Letort paper, Strategic studies institute, U.S. Army War college, Carlisle, 2011, p. 9. 
ma i projektovanje psihološke operacije protiv terorista“ ${ }^{6} \mathrm{U}$ okviru kampanje protiv terorizma trebalo bi se težiti ka uspostavljanju ravnoteže između slobode i bezbednosti, sa ciljem da se pokaže da sukob nije eskalirao. Ovo se obično radi kroz komunikaciju sa stanovništvom, kako bi se sprečila namera terorističke grupe da steknu simpatije stanovništva. Problem je u tome što ovo zahteva angažovanje većeg broja bezbednosnih snaga.

Pitanja koja bi mogla da se postave su: Da li se terorizam treba uzeti kao vojni problem? Do kojeg intenziteta terorizam predstavlja nevojni problem, odnosno kada je neophodno da se veće vojne snage angažuju?

Vojska jedne zemlje se koristi u skladu sa Ustavom i zakonima te države. lako ne postoje potpuno identični slučajevi, zapadne demokratije uglavnom imaju policiju za unutrašnju bezbednost, dok za odbranu zemlje od spoljnih pretnji imaju vojsku. Kako bi odgovorile na pretnje terorizma, neke države imaju vojne jedinice sa policijskim organima ili policijske jedinice sa vojnom strukturom, obukom i kapacitetima. To su snage odgovorne za oružani odgovor bliži vojsci, ali u sklopu Ministarstva unutrašnjih poslova. Na primer, u Turskoj, Srbiji i Francuskoj postoji žandarmerija, u Italiji karabinjeri, u Ruskoj Federaciji unutrašnja vojska, a u Makedoniji jedinica za brzo raspoređivanje.

U borbi protiv terorizma, zemlje mogu da se oslone na dva modela: da gone teroriste $u$ skladu sa zakonom o oružanom sukobu ili po nacionalnom krivičnom zakonu. „Prvi je svojstven, može se reći i luksuz koji važi za velike zemlje koje imaju veći kredibilitet u MZ. One mogu sebi da priušte proglašavanje rata protiv terorizma i da ga tretiraju kao vojnu pretnju. Drugi model je tipičan za male zemlje, ograničenjima u njihovim krivičnim zakonima sprečava se korišćenje svih kapaciteta koji stoje na raspolaganju. One razmatraju terorizam kao krivično delo i procesuiraju teroriste kao kriminalce po krivičnom zakonu zemlje. lako je ovaj model tipičan za male zemlje, on je takođe karakterističan i za liberalne demokratije“.

Kada se deluje protiv unutrašnjeg terorizma, borba protiv terorizma, za razliku od borbe protiv pobunjenika, je ograničena u pravnom okviru. Ali kada teroristička pretnja dolazi spolja, vojska može biti angažovana na više načina: kao direktna ispomoć policijskih snaga i civilnih vlasti, za demonstraciju snage i projektovanje prisustva i kontrole, ili u direktnim akcijama protiv terorista. Veće zemlje mogu sebi priuštiti i preventivnu odbranu, da deluju pre nego što budu napadnute (što je sporno u smislu Povelje UN koja se odnosi na pravo rata). „Te države mogu obavljati tajne i prikrivene operacije, obaveštajne operacije, likvidaciju vođstva, čak i da izvrše promenu vlasti, kao u Iraku“. ${ }^{\circ}$

Nakon napada u Parizu 2015. godine, Francuska je počela da razmatra nacionalnu politiku o uslovima korišćenja vojske u borbi protiv terorizma na svojoj teritoriji. Pri tome, „u borbi protiv terorizma Francuska je angažovala više od 10.000 vojnika na ulicama velikih gradova. Samo u Parizu je bilo raspoređeno oko 5.000 vojnika za patroliranje i osiguravanje važnih objekata. Građani Pariza navikli su se na prisustvo vojnika, koji su bili na ulicama nakon pokrenute operacije „Sentinel“ nakon napada na Šarli Ebdo u januaru 2015 godine“. ${ }^{9}$ Neposredno posle napada u Parizu, vojska je bila raspoređena i u Belgiji

\footnotetext{
${ }^{6}$ lbid, p. 22.

${ }^{7}$ Tayfun Erbay, The role of the military in counterterrorism: Unintended consequences, Naval postgraduate school, Monterey, California, 2012, p. 6.

${ }^{8}$ Geraint Hughes, lbid, p. 52.

${ }^{9}$ CNN News, Security boosted as Europe scrambles to handle growing threats, 2015, dostupno na: http://edition.cnn.com/2015/01/17/europe/europe-terrorism-threat/, datum pristupa 02.11.2016 godine .
} 
(Brisel), zbog prijavljenih pretnji i sumnji da teroristi planiraju napade u Belgiji. „Po prvi put posle 35 godina, zajedno sa policijom, stotine naoružanih vojnika je patroliralo Briselom, sa zadatkom da spreče terorističke napade, dok su vlasti pozivale građane da ostanu u svojim kućama, proglašavajući najviši nivo pretnjii. ${ }^{10}$ Ovo govori da savremeni terorizam prouzrokuje militarizaciju pojedinih zemalja EU po cenu veće bezbednosti.

Za razliku od IRA, čečenskih separatista, Kurdistanske radničke partije, Hamasa, Hezbolaha i drugih grupa, koje uprkos ideoloških imaju i etnoreligijske i nacionalističke motive, novi trend terorizma je globalni rat sa ciljem redefinisanja moći u međunarodnim odnosima. Samim tim, uloga vojska u savremenoj borbi protiv terorizma postaje sve značajnija, a njena upotreba postaje nužno zlo, neophodno za postizanje pobede nad terorizmom.

Tamo gde postoji previše policajaca, ne postoji sloboda, a tamo gde postoji previše vojnika, ne postoji mir, reči su kineskog pesnika Lin Jutanga. Ravnotežu između to dvoje nije lako pronaći, pogotovo kada se radi o misijama unutar neke zemlje. U tom kontekstu, evropske države, poput Nemačke i Austrije, razmišljaju o korišćenju vojnika u misijama unutar države, a sve radi efikasnije borbe protiv savremenog terorizma.

Ministar odbrane Austrije, Hans Peter Doskozil namerava, zbog pretnje od napada, ojačati elitnu jedinicu austrijske vojske. Specijalna jedinica treba dobiti veći broj pripadnika i dodatnu opremu, a Doskozil je najavio da će se u opremu investirati 35 miliona evra. On veruje da će borba protiv terorizma postati sve više zadatak vojske.

Dalje, Urlih Kuen sa Instituta za bezbednosne studije Univerziteta u Hamburgu ističe da je upotreba naoružanih vojnika za unutrašnje misije u Nemačkoj jako retka i dozvoljena je samo u ekstremnim slučajevima. On smatra da su primeri Francuske i Belgije, gde se vojnici koriste u raznim situacijama na ulici, pokazali da prisustvo vojske ne mora značiti da postoji manja opasnost od napada. Baš situacije u tim zemljama pokazuju da je, kada se radi o muslimanima, važnija dobra integracija nego bilo šta drugo. U tom smeru, Nemačka bi morala naučiti od grešaka drugih i, na primer, omogućiti obrazovanje nemačkih imama na univerzitetima. Sa druge strane, u slučaju upotrebe vojske unutar zemlje, postoji opasnost da bi vlasti mogle početi razmišljati o tome da se bezbednosni problemi mogu rešiti samo vojskom. Istorija Nemačke je pokazala da postoje stvari koje govore protiv mešanja vojnika i civila.

Postoje nekoliko razloga koje ograničavaju upotrebu nemačke vojske u unutrašnjim misijama: nemačka policija ima specijalističku obuku vezanu za unutrašnju bezbednost, koja traje tri godine, dok vojnici nemaju tu vrstu obuke; vojska nema ovlašćenja koje ima policija i ne smeju, na primer, hapsiti ljude ili vršiti kontrole; rad policije je u nadležnosti nemačkih regija, ${ }^{11}$ a kada bi došlo do upotrebe vojnika unutar zemlje, postojala bi mogućnost da ih one iskoriste kako bi smanjile izdatke svojih policija; nemačka vojska je trenutno preopterećena zbog misija van zemlje.

\footnotetext{
${ }^{10}$ Aljazeera news, Army patrols deserted streets as Brussels on edge, 22.11.2015 godine, dostupno na: http://www.aljazeera.com/news/2015/11/army-patrols-deserted-streets-brussels-high-alert151121160847096.html, datum pristupa 15.11.2016 godine.

${ }^{11}$ U Nemačkoj svaka regija ima specijalnu policijsku jedinicu, koja se koristi u talačkim krizama i u borbi protiv terorizma. U slučaju kada su policijske snage neke regije preopterećene, vlasti mogu tražiti da se tamo pošalju policajci iz drugih regija. Policijska jedinica koja je zadužena za borbu protiv terorizma na nivou države je GSG9 , a od prošle godine postoje i takozvane „BFE plus“ jedinice. Te jedinice su, tvrde eksperti, oformljene nakon napada na redakciju satiričnog magazina Šarli ebdo u Francuskoj. One posebno brzo reagiraju u ekstremnim slučajevima i mogu uvek pomoći GSG-9 i policijama drugih zemalja.
} 
Postavlja se pitanje da li bi upotreba vojske unutar Nemačke bila korisna kada bi se desio napad na više mesta istovremeno, da li bi vojska reagovala brže od nemačke vojne policije „Feldjager“. U tom slučaju, vojnici bi se mogli iskoristiti da osiguraju velika područja, a ne da razoružaju i onesposobe napadače. Može se zaključiti da upotreba vojske unutar zemlje ne znači da bi ona zamenila policiju, već bi sadejstvovala sa njom ka ostvarivanju zajedničkog cilja, pobede nad savremenim terorizmom.

\section{Uticaj upotrebe vojske u borbi protiv savremenog terorizma na civilno društvo i međudržavne odnose}

Pozitivna strana upotrebe vojske u borbi protiv terorizma se ogleda u mogućnosti brzog neutralisanja postojećih pretnji i demonstraciji države da se odlučno odbrani od budućih pretnji. Pri tome, vojska bi se morala koristiti u skladu sa državnim zakonima i da uzajamno deluje sa jedinicama koje su nadležne za borbu protiv nekonvencionalnih pretnji. Cilj mora biti da se sukob održi na niskom nivou intenziteta kako se ne bi izazvala dodatna značajna šteta i da postoji dobra koordinacija i sinhronizacija vojske sa policijskim snagama, koje su obično bolje upoznate sa situacijom na terenu i sa stanovništvom.

Većina evropskih zemalja je izabrala policijski pristup u borbi protiv terorizma, nakon iskustava koja su pokazala da je ovaj pristup efikasniji od vojnog. „Zapadne demokratije su uvek bile u nedoumici kako da se zaštite od terorizma i da ujedno uspostave ravnotežu između upotrebe vojnih kapaciteta i ometanja normalnog života građana“. ${ }^{22}$ „Britanija i Španija su primeri gde se u početku primenjivao vojni pristup, a onda se uloga vojske u borbi protiv terorizma smanjila na račun policije pri čemu se problem tretirao kao krivično delo“. ${ }^{13}$ U Severnoj Irskoj, početna intervencija bila je zasnovana na zakonu o oružanom sukobu, a zatim se prešlo na gonjenje IRA u skladu sa krivičnim zakonom. Ovaj primer je uspešna studija o primeni vojske u borbi protiv terorizma, gde se „sa pravim politikama postižu bolji rezultati nego što bi bio slučaj sa izričitom upotrebom konvencionalnih snaga“. ${ }^{14}$

Negativne posledice koje proizlaze od upotrebe vojske u borbi protiv terorizma mogu biti: eskalacija sukoba, stvaranje novih terorista i dodeljivanje vojsci veće moći, što može predstavljati pretnju demokratiji.

Eskalacija sukoba se manifestuje u trenutku kada vojska izađe na ulice gradova i započne da deluje sa većom snagom, što u očima građana znači rat. U pokušaju da brzo okonča sukob, najverovatnije bi se angažovala prekomerna snaga koja bi nanela veća i nepotrebna oštećenja infrastrukture. Ovo bi dalje moglo uzrokovati ekonomske, socijalne i političke posledice, kao i posledice po spoljnu politiku. „Problem sa ovakvom upotrebom vojske je linearno postavljanje vojne organizacije protiv pretnje koja je nelinearna, kompleksna i koja uključuje razne aspekte društvenog života zemlje“. ${ }^{15}$

\footnotetext{
${ }^{12}$ Ian M. Cuthbertson, The Nature of the Terrorist Threat and National Responses to Terrorism: The British Case, in National Counter-Terrorism Strategies, IOS Press, 2006, p.128.

${ }^{13}$ Mikhail Rykhtik, Asymmetric Threats and Counter-Terrorism Strategies in Russiain National Counter-Terrorism Strategies, IOS Press, 2006, p.166.

${ }^{14}$ Tayfun Erbay, The role of the military in counterterrorism: Unintended consequences, p. 13.

${ }^{15}$ Ibid, p. 7.
} 
To znači da ukoliko vojska nije sposobna za nekonvencionalnu borbu protiv terorista, koji su u suštini neregularne snage, moglo bi se doći do neželjenog efekta i eskalacije sukoba. Stoga, u borbi protiv terorizma, u principu bi se mogle koristiti snage specijalnih jedinica.

Praksa pokazuje da angažovanje vojske u operacijama protiv terorista u zemlji može da izazove problem sa legitimitetom, kao i do stvaranja novih terorista. S obzirom na neselektivnu upotrebu snaga, dolazi se do kolateralne štete, što stvara ogorčenje i frustraciju stanovništva. Ukoliko se stanovništvo saoseća sa teroristima, moglo bi da dođe čak i do priključivanje građana u terorističke redove. „Sve one zemlje koje u borbi protiv terorizma uključuju vojsku, rizikuju da stvore kontra-reakcije i umesto smanjivanje broja terorista da u stvari doprinesu ka povećanju njihovog broja“. ${ }^{16}$

Ratovi u Iraku i Avganistanu su dokazali da se teroristi gotovo uvek kriju među civilnim stanovništvom, terajući koalicione snage da načine što veće kolateralne štete i na taj način prouzrokuju bes kod stanovništva. U operacijama u kojima je vojska angažovana sa konvencionalnim sredstvima u savremenoj borbi protiv terorizma, neizbežno je da se greške i kolateralne štete prave na terenu.

Obično, teroristi su oni koji ne poštuju zakon oružanog sukoba i pravila ratovanja. Međutim, kada se zemlje suprotstavljaju sa prekomernom silom, onda je neizbežno da se prekorače ovlašćenja i da vojska započne da krši zakon. Takvi scenariji su priželjkivani od strane terorista, jer se na taj način pretvaraju u žrtve koje grade svoju legitimnost. Postoje brojni slučajevi u kojima male terorističke grupe rastu u masivnim pobunjeničkim pokretima i grupama branitelja ljudskih prava, samo zato što su države neodgovorno koristile vojsku da uguše njihove aktivnosti.

Budući da je između terorizma i pobune linija tanka, neke terorističke grupe grade političku platformu sa kojom bi bili predstavljeni kao legitimne snage u zaštiti prava određenih grupa. Kada država preuzima vojnu akciju protiv terorista, to može dovesti do podsticaja intenzivnog regrutovanja građana u redovima terorističkih grupa. Na taj način, vojska je od terorista stvorila mučenike i doprinela je njihovoj još većoj koheziji i popularnosti. Postoje brojni primeri u kojima teroristi često dobijaju podršku od lokalnog stanovništva u operativnom okruženju gde deluju, a akcija protiv njih samo povećava njihov broj preko motivisanja novih regruta. Ovo može biti potvrđeno podacima koji govore da je „broj terorista, članova ID u Siriji značajno porastao nakon niza operacija preuzetih od strane nekoliko zemalja koje su intervenisale vazdušnim napadima“. ${ }^{17}$ Primer za to je bila i strategija ETA u Španiji, „koja je uspela da regrutuje nove članove preko iznuđivanja represivne akcije od strane države".

Kao što je prethodno $u$ tekstu istaknuto, treća negativna posledica upotrebe vojske $u$ borbi protiv terorizma je dodeljivanje vojsci veće moći. „Pri upotrebi vojske u borbi protiv terorizma postoji verovatnoća od poremećaja civilno-vojnih odnosa u državi“. ${ }^{18}$ To je moguće jer „da bi vojska bila efikasna, ona bi trebala dobiti veća ovlašćenja, od uobičajenih, i ulogu i zadatke koji obično pripadaju civilima“. ${ }^{19}$

\footnotetext{
${ }^{16}$ Ibid, p.3.

${ }^{17}$ CNN News, ISIS can 'muster' between 20,000 and 31,500 fighters, 12.09.2014 godine, dostupno na: http://edition.cnn.com/2014/09/11/world/meast/isis-syria-iraq/, datum pristupa 18.11.2016. godine.

${ }^{18}$ Biljana Vankovska-Cvetkovska, Vojskata i demokratijata, NIP Nova Makedonija, Skoplje, 1995, str. 89.

${ }^{19}$ Tayfun Erbay, The role of the military in counterterrorism: Unintended consequences, nav. delo, p. 5.
} 
Rečju, na račun veće bezbednosti, javlja se pretnja od gubitka slobode. Samim tim što vojska poseduje mnogo veću fizičku i vatrenu moć, ona se može pretvoriti u osnovni generator bezbednosti i na taj način postepeno nametnuti kao glavni faktor opstanka države.

Postoje brojni primeri u kojima vojska ima svoj primat i u kojima se ona polako pretvara u instituciju koja je „država u državi“. Ovo „pozicioniranje vojske u društvu može da dovede do militarizacije političkog sistema i veće uloge vojnih lidera u političkom procesu“ ${ }^{20}$

Države koje se bore protiv terorizma u saglasnosti sa zakonitostima oružanih sukoba tretiraju borbu protiv terorizma kao rat i koriste sve raspoložive kapacitete. Ovo sebi ne mogu priuštiti sve zemlje, jer međunarodna reakcija prema različitim zemljama varira u zavisnosti od njihove političke, ekonomske i vojne moći. One zemlje koje mogu da sebi priušte upotrebu velikih snaga tretiraju teroriste kao nacionalnu, regionalnu ili globalnu pretnju, i otvoreno primenjuju oružanu silu kako bi ih uništili. Ali, tu postoji rizik od gubitka legitimiteta u borbi protiv terorizma i osude zemlje od strane MZ. Sa ovim se suočila Ruska Federacija u vreme Borisa Jeljcina, u periodu Prvog čečenskog rata, kada je vodila borbu protiv terorizma na svojoj teritoriji. Ruska Federacija je od strane zapadnih zemalja bila osuđena kao agresor zbog upotrebe nesrazmerne sile, jer je ruska vojska prouzrokovala značajnu kolateralnu štetu.

To znači da „u pokušajima borbe protiv terorizma, države mogu da koriste metode sa kojima je rezultat više štetan za demokratiju nego što je to sam terorizam". ${ }^{21}$ Istovremeno, između ostalog „postoji i rizik od gubitka civilnog nadzora vojne moći od strane civilnih struktura, kao što se desilo u Argentini, Brazilu i Čileu u periodu 60-ih i 80-ih godina prošlog veka".

Moderan primer je iskustvo „sa angažovanjem ruske vojske u borbi protiv čečenskih separatista u Drugom čečenskom ratu, što je dalje izazvalo negativne efekte u procesu demokratizacije i nazadovanje političkih reformi u smislu povratku ka autokratiji u zemlji“. ${ }^{23}$ Vladimir Putin je na račun vojnih uspeha naglo stekao popularnost, što mu je dalje omogućilo da ojača političku poziciju u stilu tradicionalne ruske moći.

Prema tome, postoji široko liberalno mišljenje da, svi pokušaji države da angažuje vojsku sa većim ovlašćenjima doprinose da se građanska sloboda ograniči. „Ljudi, svesno i dobrovoljno, zbog iluzije o bezbednosti se odriču slobode, dok u isto vreme, vojni odgovor protiv terorizma ne daje željene rezultate". ${ }^{24}$

$S$ druge strane, rastuća uloga vojske u savremenoj borbi protiv terorizma ima potencijal da militarizuje međunarodnu politiku jer političari mogu početi da se previše oslanjaju na vojsku i da probleme rešavaju jedino sa upotrebom sile.

Borba protiv terorizma je asimetrična jer „teroristi, kao nedržavne akteri, raspolažu sa neuporedivo manjim kapacitetom, u odnosu vojske i policije. Baš to im daje prednost u odnosu na nezgrapne vojne formacije kojima mogu na relativno lak način da ugroze sna-

\footnotetext{
${ }^{20}$ Biljana Vankovska-Cvetkovska, Ibid., p. 92.

${ }^{21}$ Martha Crenshaw, Introduction in The Consequences of Counterterrorism, New York: Russell Sage Foundation, 2010, p. 2.

22 Tayfun Erbay, Ibid, p.11.

${ }^{23}$ Geraint Hughes, The military's role in counterterrorism: examples and implications for liberal democracies, p. 8.

${ }^{24}$ FCNL, The Illusion of Security, 11.06.2011 godine, dostupno na: https://www.fcnl.org/updates/the-illusionof-security-12, datum pristupa 17.11.2016. godine.
} 
gu i istovremeno iskoriste njihovu ranjivost“. ${ }^{25}$ To je jedan od razloga što mnoge studije ukazuju da vojno rešenje u borbi protiv terorizma nije efikasno jer se sukob samo dodatno rasplamsava, pa se od terorizma dolazi do pojave klasične pobune.

Da li je vojna snaga efikasna u borbi protiv terorizma i dalje ostaje pitanje bez jasnog odgovora, „zato što se vojska obično fokusira na pobedu, dok praksa pokazuje da mora da se fokusira na efikasnost, i to merljivu uspehom, da se smanji uništavanje infrastrukture i uzrokovanje kolateralne štete". ${ }^{26}$

Ono što može da se konstatuje je da upotreba vojske u borbi protiv terorizma može istovremeno biti i korisna i štetna, bez razlike da li se vojska upotrebljava na domaćem terenu ili van nacionalnih granica.

„SAD u poslednjih 40 godina nisu uspele da identifikuju pravilnu strategiju vezanu za borbu protiv terorizma jer se previše oslanjaju na vojni pristup u odnosu na razumevanje izvora terorizama“. ${ }^{27}$ I pored toga, SAD i ostale zapadne demokratije idu ka sve većoj upotrebi vojske u borbi protiv terorizma, što može da znači promenu paradigme međunarodne bezbednosti, a time i izgleda modernog društva. ${ }^{28}$

Međutim, i pored oprečnih stavova i mišljenja, postoje određeni uslovi koji bi trebali biti ispunjeni da bi se vojska uključila u borbu protiv terorizma, na osnovu odluka nadležnih državnih organa u skladu sa zakonom:

- „Kada je teroristička aktivnost prerasla u gerilska dejstva ili ustanak, a policija nije u stanju da reši bezbednosni problem.

- Kada je država iznenada upala u talačku krizu većih razmera i koja preti da ugrozi njene vitalne interese.

- Kada teroristi upotrebe NHB sredstva i izazovu NHB incident koji predstavlja bezbednosni rizik po stanovništvo, a jedino vojska je sposobna da izvrši dekontaminaciju i sprovede druge mere i aktivnosti kojima se sprečava ugrožavanje života građana i životne sredine.

- Kada teroristička organizacija izvede teroristički akt otmice plovećeg objekta na rekama na teritoriji sopstvene države, a koji prevozi ljude, materijalna dobra ili opasne materije u situaciji kada angažovanje policijskih antiterorističkih jedinica nije dovoljno" ${ }^{29}$

Kako bi se preventivno delovalo i na duge staze vodila borba protiv savremenog terorizma neophodno je napore usmeriti na aktivnosti države i društva radi suzbijanja osnovnih uzroka nastanka ove pojave u pravcu jačanja osnovnih poluga države i društva, njihove snage, kvaliteta, vitalnosti i demokratičnosti, koji se nalaze u njihovoj osnovi, zatim razvojem pravne države i sistema zaštite sloboda i prava građana i učvršćivanjem društvenih odnosa u svim segmentima života. ${ }^{30}$

\footnotetext{
${ }^{25}$ Mikhail Rykhtik, Asymmetric Threats and Counter-Terrorism Strategies in Russiain National CounterTerrorism Strategies, p. 169.

${ }^{26}$ Ibid, p. 174

${ }^{27}$ Louise Shelley, Countering Terrorism in the US: The Fallacy of Ignoring the Crime-Terror Nexus in National Counter-Terrorism Strategies, IOS Press, 2006, p. 203.

${ }^{28}$ Čarli Kegli, Judžin Vitkof, Svetska politika - trend i transformacija, Centar za studije Jugoistočne Evrope, Fakultet političkih nauka, Diplomatska akademija, Beograd, 2004, str. 658.

${ }^{29}$ Gaćinović Radoslav, „Uloga vojske u suprostavljanju terorističkim aktivnostima“, Vojno delo, 2/2015, Beograd, str. 180.

${ }^{30}$ Isto, str. 182-183.
} 


\section{Zaključak}

lako se borba protiv terorizma u vojnoj nauci tretira kao sukob niskog intenziteta, događaji u poslednje dve decenija pokazuju da su se pojavile terorističke organizacije koje nameću sukob visokog intenziteta.

Neophodno je napraviti razliku o kakvim se teroristima radi, jer postoji velika razlika u motivima transnacionalnog i globalnog terorizma, koji ima globalne ambicije, za razliku od lokalnih (regionalnih) terorističkih grupa koje imaju lokalne i ograničene ambicije. Ovi drugi, često mogu biti pobunjenici sa drugim motivima, kojima države daju preveliko značenje terorista samo radi njihovog delegitimiranja ili iznuđivanja međunarodne podrške za njihovo suzbijanje.

Kada se govori o terorizmu tada je bitno naglasiti da tradicionalni terorizam konvencionalnim oružjem kao i tradicionalni načini ratovanja sve više „izumiru“ i pripadaju istoriji, a sve više i češće se pribegava nekonvencionalnim oblicima ratovanja, pa tako i terorizmu, koji su daleko jeftiniji, brži, učinkovitiji i postižu neuporedivo bolje i brže efekte prema onima kojima su usmereni. U pokušaju da unište teroriste, države rizikuju da koristeći ogromnu snagu neminovno dovode do ograničavanja slobode i pojava kolateralnih šteta civilnog stanovništva. Teroristi na taj način realizuju svoje ciljeve, pretvarajući demokratske države u destabilizatore mira.

Sve analize pokazuju da upotreba vojske u borbi protiv terorizma treba da bude poslednja opcija država. Cena koju bi moderno demokratsko društvo moralo platiti može biti eskalacija sukoba, ograničavanje slobode i potencijalno stvaranje novih terorista. Logika kaže da je neophodno da se preispita priroda terorizma kao fenomen i da se leči bolest, a ne simptomi. Dešavanja na Bliskom Istoku mogu se smatrati kao posledica vojničkog pristupa u „dugom ratu“ zapadnih zemalja u borbi protiv terorizma. Međutim, iako iskustvo pokazuje da je policijski pristup efikasniji nego vojni i da je bolje da se problem terorizma tretira kao krivično delo, moderni terorizam ima funkcije sa kojim naliči na pobunu u kojoj se koriste terorističke metode. Ova mutacija globalne pretnje terorizma će neminovno uticati na promenu inače osetljive uloge vojske u demokratskim državama.

U budućnosti, države će se suočiti sa dilemom o veličini vojne snage i operativnom pristupu u korišćenju vojske usled sve većeg preklapanja unutrašnjih i globalnih pretnji. Ako se zbog svog transnacionalnog karaktera terorizam počne smatrati kao vojni problem, neophodan će biti globalni odgovor i planiranje upotrebe vojske u koalicionim operacijama. Izvan tog konteksta, pitanje za političke lidere će biti sadržano u dilemi između sprovođenja militarizacije društva i istovremenog održanja ravnoteže između bezbednosti i slobode.

Ako je upotreba vojske apsolutno neophodna i odlučujuća u savremenoj borbi protiv terorizma, onda bi se to moralo uraditi zajedničkim naporima zemalja u okviru međunarodnog prava. Pri tome, da bi se efikasno koristila, vojska bi morala dobiti veća ovlašćenja, što podrazumeva i neophodnost promena postojećih zakona koja su na snazi u raznim zemljama.

\section{Literatura}

[1] Andrew W. Neal, Exceptionalism and the Politics of Counter -Terrorism: Liberty, Security and the War on Terror, Routledge, London, 2010.

[2] Vankovska-Cvetkovska Biljana, Vojskata i demokratijata, NIP Nova Makedonija, Skopje, 1995.

[3] David Benest, British Leaders and Irregular Warfare in The Moral Dimension of Asymmetrical Warfare, The Netherlands, 2009. 
[4] Geraint Hughes, The military's role in counterterrorism: examples and implications for liberal democracies, Letort paper, Strategic studies institute, U.S. Army War college, Carlisle, 2011.

[5] Gaćinović Radoslav, „Uloga vojske u suprotstavljanju terorističkim aktivnostima“, Vojno delo, 2/2015, Beograd.

[6] Ian M. Cuthbertson, The Nature of the Terrorist Threat and National Responses to Terrorism:The British Case, in National Counter-Terrorism Strategies, IOS Press, 2006.

[7] Louise Shelley, Countering Terrorism in the US: The Fallacy of Ignoring the Crime-Terror Nexus in National Counter-Terrorism Strategies, IOS Press, 2006.

[8] Martha Crenshaw, Introduction in The Consequences of Counterterrorism, New York: Russell Sage Foundation, 2010.

[9] Mikhail Rykhtik, Asymmetric Threats and Counter-Terrorism Strategies in Russiain National Counter-Terrorism Strategies, IOS Press, 2006.

[10] Tayfun Erbay, The role of the military in counterterrorism: Unintended consequences, Naval postgraduate school, Monterey, California, 2012.

[11] Aljazeera news, Army patrols deserted streets as Brussels on edge, 22.11.2015 godine, dostupno na: http://www.aljazeera.com/news/2015/11/army-patrols-deserted-streets-brussels-highalert-151121160847096.html, datum pristupa 15.11.2016 godine.

[12] CNN News, ISIS can 'muster' between 20,000 and 31,500 fighters, 12.09.2014. godine, dostupno na: http://edition.cnn.com/2014/09/11/world/meast/isis-syria-iraq/, datum pristupa 18.11.2016 godine.

[13] CNN News, Security boosted as Europe scrambles to handle growing threats, 2015, dostupno na: http://edition.cnn.com/2015/01/17/europe/europe-terrorism-threat/, datum pristupa 02.11.2016 godine.

[14] FCNL, The Illusion of Security, 11.06.2011 godine, dostupno na: https://www.fcnl.org/updates/the-illusion-of-security-12, datum pristupa 17.11.2016 godine.

[15] Geir Moulson, German Cabinet Approves Military Intervention Against ISIS In Syria, The World Post, 2015, dostupno na: http://www.huffingtonpost.com/entry/germany-isissyria_565dae34e4b072e9d1c32977, datum pristupa 30.10.2016 godine. 